Www.jmscr.igmpublication.org

Index Copernicus Value: 79.54

ISSN (e)-2347-176x ISSN (p) 2455-0450

crossref DOI: https://dx.doi.org/10.18535/jmscr/v7i6.65

\title{
Efficacy of negative pressure wound therapy in surgical wound management: an evidence based prospective randomised study
}

\author{
Authors \\ Pinaki Roy ${ }^{1}$, Swarup Chakraborty ${ }^{2}$ \\ Corresponding Author \\ Swarup Chakraborty
}

\begin{abstract}
Aims and Objectives: To find out the efficacy of negative pressure on healing of complex acute and chronic wounds and contaminated laparotomy wounds.

Methods: This prospective randomized experimental study was conducted on a total of 64 consecutive patients with different types of surgical wounds. They were randomly divided into two equal groups. There were 32 patients in each group. The study group or group A received negative pressure wound therapy, whereas group $B$ or control group received conventional normal saline gauze dressings. The mean duration of treatment was 4 weeks (range 2 to 6 weeks). The different parameters of wound healing were analyzed using Chi-square test and $\mathrm{Z}$ test.

Results: Patients with NPWT had faster disappearance of wound exudates, earlier appearance of granulation tissue and faster wound healing. No significant difference in bacterial clearance was found. Pain during dressing changes due to in growth of granulation tissue was the most common complication found in NPWT.

Conclusions: NPWT is associated with faster wound healing with fewer acceptable complications. It is particularly effective in dealing with complex or difficult surgical wounds.

Keywords: wound exudates, sub atmospheric pressure, surface area of wound, granulation tissue, bacterial bio burden, negative pressure, wound closure.
\end{abstract}

Introduction and Review of Literature

Negative pressure wound therapy (NPWT), sometimes referred to as vacuum-assisted closure has a unique capacity of wound healing, covering a range of complex acute, subacute and chronic wounds. NPWT technique uses a dressing system that applies subatomspheric pressure on the wound. It can be used for continuous, intermittent and sinusoidal therapy. NPWT was developed in Germany and United states during the 1990's 1, 6,7 and the original description of negative pressure - assisted wound closure was presented by Argenta and associates in $1997^{1}$.

Scientifically and clinically proven mechanism of action associated with NPWT:

- Removes edema and exudate ${ }^{1,13}$

- Increases perfusion, promotes growth factors ${ }^{1.3}$

- Provides moist wound healing environment.

- Promotes granulation tissue formation ${ }^{13}$ and improves wound depth ${ }^{2}$

- Prepares the wound bed for final closure. 
Several studies depict that NPWT increases capillary caliber, endothelial proliferation and angiogenesis ${ }^{4}$. The role of this therapy in reducing bacterial bioburden in contaminated wound is controversial $^{12}$. Some studies illustrate that NPWT promotes bacterial clearance in contaminated wounds which may contribute wound healing. On the other hand some studies showed that bacterial colonization increased considerably with the application of NPWT. However, it was consistently found that NPWT prevents $^{9,10}$ surgical site infection.

NPWT appears to be an effective way to accelerate healing of various types of wounds like diabetic ulcer ${ }^{16}$, traumatic wounds, skin grafts and flaps $^{3,15}$, pressure ulcers ${ }^{14}$, partial thickness burns $^{17}$, surgical wounds ${ }^{8,9,10}$, necrotizing fascitis, pilonidal sinus wounds. On the other hand there are some wounds where NPWT is contraindicated $^{18}$. These wounds are ${ }^{18}$ :

$>$ Wounds containing necrotic tissue and escher

$>$ Wounds containing malignant tissues

$>$ Untreated osteomyelitis

> Wounds with unexplored/ visible fistula

$>$ Presence of untreated coagulopathy or clotting disorder.

> Wounds with exposed blood vessels, nerves, organs, anastomotic sites and ischemic wounds.

NPWT is not free from complications. Complications commonly seen in association with NPWT are pain during dressing changes due to ingrowths of granulation tissue ${ }^{22}$, peri wound blistering and ecchymosis, superficial skin necrosis and rarely sepsis.

Procedure: NPWT system consists of a nonadherent porous foam dressing made of black polyurethane. This foam dressing is cut to the size of wound and placed over the wound. Now a tube drain is attached to the foam dressing. Finally the foam and adjacent skin is sealed with a transparent plastic film and the other end of the tube drain is connected to a vacuum machine to give negative pressure. When negative suction pressure is applied, tissue fluid and exudates come out of the wound into the tube drain and finally collected into a sealed container.

In small or shallow wounds gauze dressing may be used instead of foam dressing. The negative pressure can be used continuously or intermittently and should be between -50 to -175 $\mathrm{mmHg}$. Commonly the pressure is set at$125 \mathrm{mmHg}^{5,18}$ on a continuous setting. The pressure may be increased by $25 \mathrm{mmHg}$ in excessive drainage, large wound volume. Again the pressure can be titrated down by $25 \mathrm{mmHg}$ in conditions like extremes of age, compromised nutrition, risk of excessive bleeding (anticoagulant therapy), circulatory compromise (peripheral vascular disease), excessive growth of granulation tissue, pain or discomfort not relieved by appropriate analgesia, peri wound or wound ecchymosis. The dressing should be changed every 48 to 72 hours. In presence of infection dressing should be changed early.

\section{Materials and Methods}

The study was conducted in a tertiary care centre in Kolkata in the year 2018. Study population consisted of 32 patients of various types of surgical wounds undergoing NPWT and designated as group A or study group, and 32 patients with different types of surgical wounds receiving normal saline gauze dressings (NSGD) and designated as group B or control group. The study design was a prospective randomized experimental study.

Before application of NPWT or NSGD, all dead and devitalized tissues were removed from wound by debridement, where applicable. Dressings of NPWT were changed on weekly basis and dressings of NSGD were changed on alternate day. All patients were initially prescribed broad spectrum antibiotics. On every week, wound swabs were sent for $\mathrm{c} / \mathrm{s}$.Depending on c/s report specific antibiotics were given. The following parameters were recorded with passage of time:

1) Age of patient

2) Sex 
3) Surface area and depth of wound

4) Disappearance of exudate

5) Appearance of granulation tissue

6) $\mathrm{C} / \mathrm{S}$ patterns of wound swab

7) Time required appearing healthy wounds amiable for surgical closure

8) Length of hospital stay

9) Cost of treatment

10) Any complications like pain, peri wound blistering and ecchymosis, skin necrosis.

\section{Inclusion criteria were}

1) Age: 20 to 65 years

2) Absence of life threatening comorbid conditions

3) Any complex acute or chronic wounds and contaminated laparotomy wounds

4) Absence of any contraindication to NPWT

\section{Exclusion criteria were:}

1) Age <20years and $>65$ years

2) Presence of life threatening comorbid conditions

3) Wounds having contraindication for NPWT

4) Clean incised wounds.

\section{Results and Analysis}

The different parameters of wounds during healing were compiled, tabulated and analyzed. The data were analyzed using chi-square test and $\mathrm{Z}$ test. The mean follow up of all patients was 4 weeks (range-2 to 6 weeks).

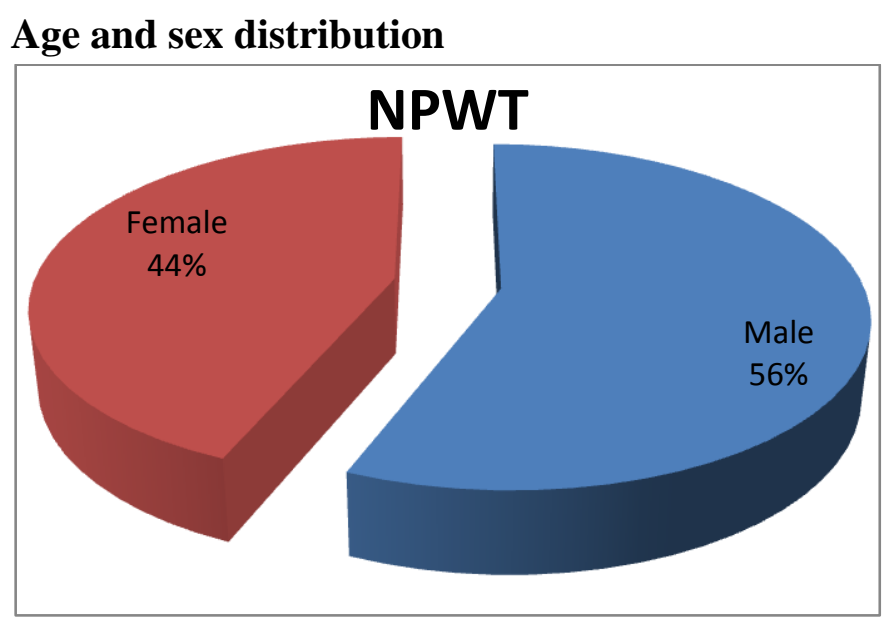

Of 32 group A patients $(n=32)$ who received VAC therapy, $18(56.25 \%)$ were male and $14(43.75 \%)$ were female with an average age of 42.2 years (range 20 to 65 years).

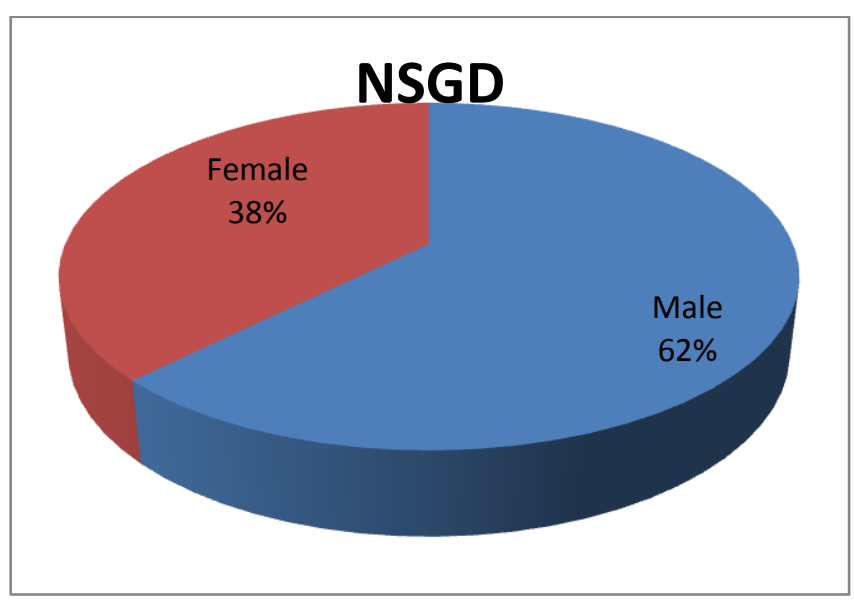

Of the 32 patients $(\mathrm{n}=32)$ who received NSGD, $20(62.5 \%)$ were male and $12(37.5 \%)$ were female with an average age of 40.4 years (range 20 to 65 years).

\section{Status of wound exudates}

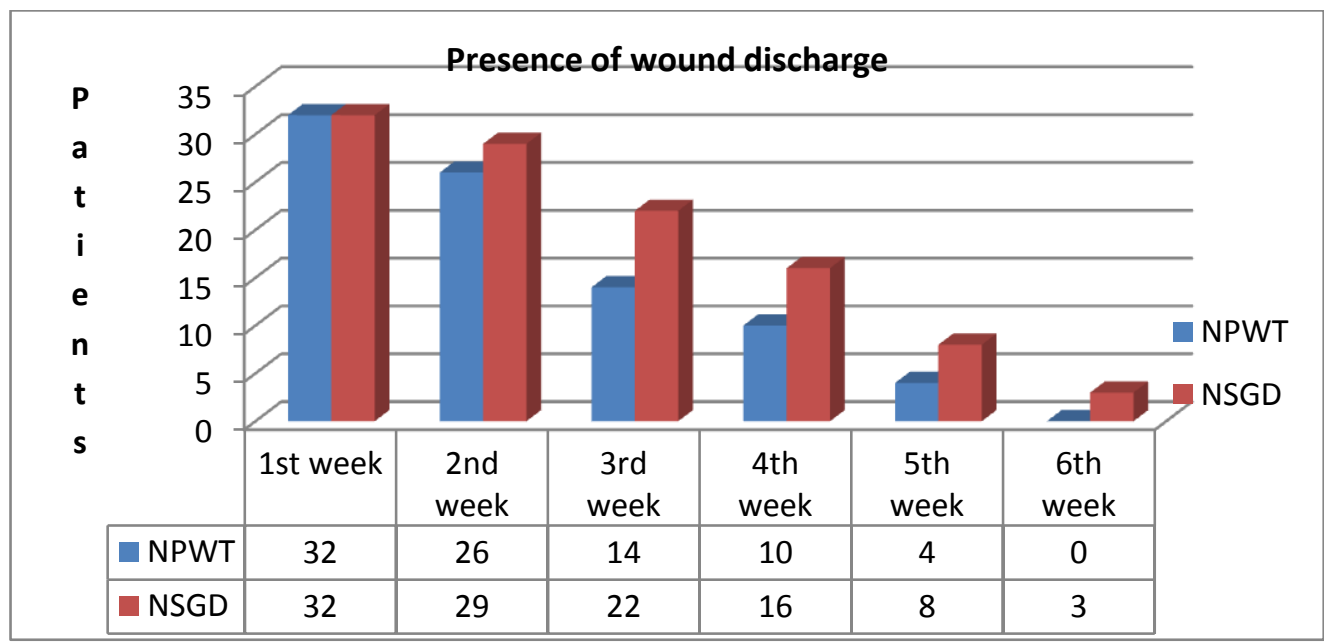


At the end of $1^{\text {st }}$ week all patients of group A and group B had wound discharge. The disappearance of wound discharge over the observation period was calculated. The rate of disappearance of wound exudates was found to be faster in group A compared to group B. At the end of $3^{\text {rd }}$ week $14(43.75 \%)$ patients of group A and 22(68.75\%) patients of group $\mathrm{B}$ had wound discharge. This finding was found to be significant $(\mathrm{P}=0.043)$.It is also seen that exudation of wound ceased in all patients of group A in $6^{\text {th }}$ week, whereas $3(9.38 \%)$ patients of group B had continuing discharge at $6^{\text {th }}$ week. At the end of $6^{\text {th }}$ week these $3(9.38 \%)$ patients of group B had undergone NPWT due to presence of excessive wound discharge. Following NPWT, wound discharge disappeared within 2 weeks and healthy granulation tissue appeared.

\section{Appearance of granulation tissue}

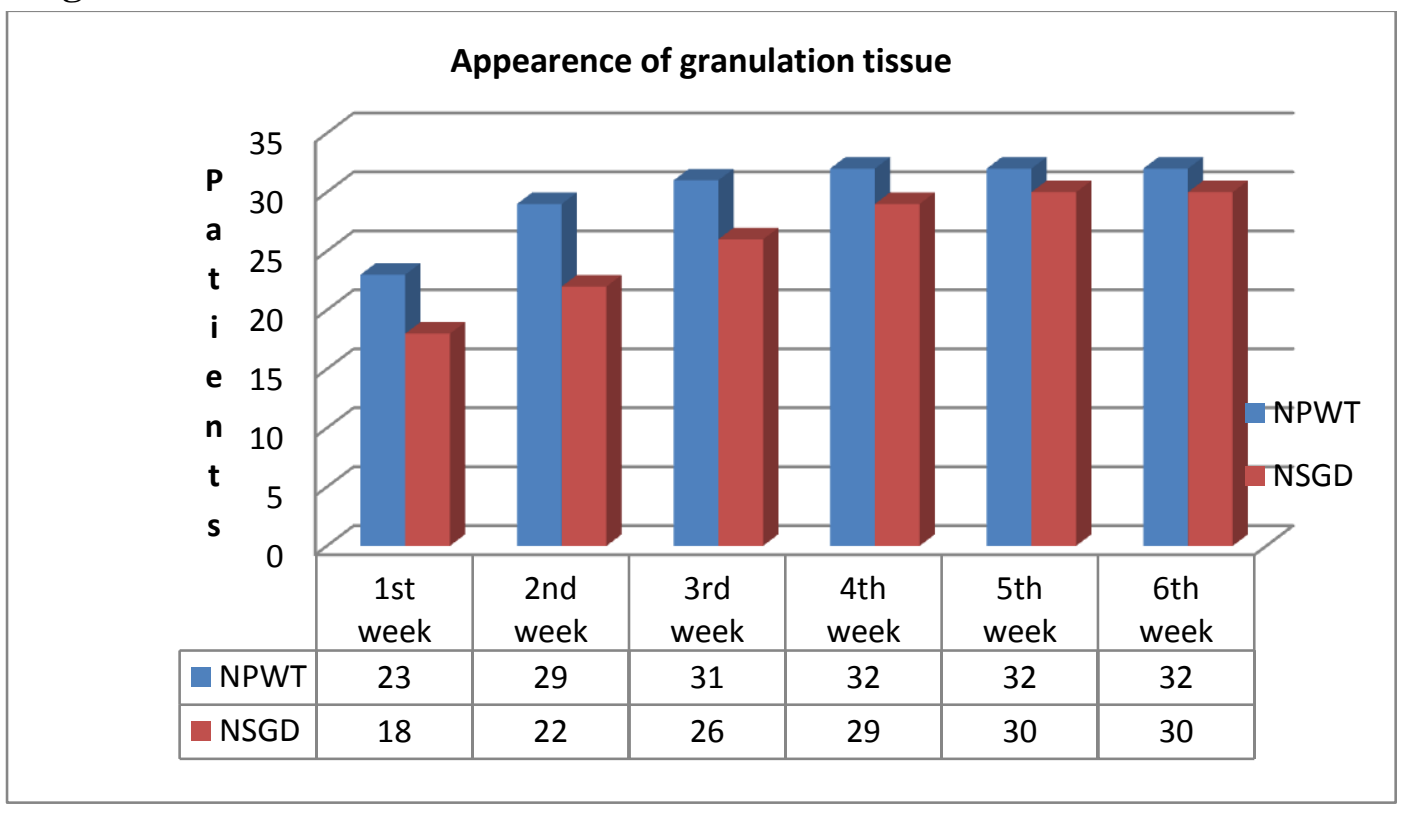

It was also observed that the formation of granulation tissue in patients of NPWT was faster and stastically significant $(\mathrm{p}<0.05)$. At the end of $1^{\text {st }}$ week granulation tissue did not appeared in 9 patients $(28.12 \%)$ in group A and 14 patients $(43.75 \%)$ in group B. Out of 9 patients of group A , granulation tissue appeared at the end of $2^{\text {nd }}, 3^{\text {rd }}$ and $4^{\text {th }}$ week in 6 patients, 2 patients and 1 patients respectively. The appearance of granulation tissue in remaining group $\mathrm{B}$ patients (14) at the end of $2^{\text {nd }}, 3^{\text {rd }}, 4^{\text {th }}, 5^{\text {th }}$ and $6^{\text {th }}$ week were $4,4,3,1,0$ patients respectively. At the end of $2^{\text {nd }}$ week, granulation tissue appeared in $29(90.625 \%)$ patients in group A and 22(68.75\%)in group B, where the $p$ value is 0.029 . The granulation tissue did not appear in 2 patients of group B at the end of $6^{\text {th }}$ week and later effectively received NPWT.

\section{Wound surface area}

The wound surface area was reduced more in the NPWT group than in the control group. At the end of $2^{\text {nd }}$ and $3^{\text {rd }}$ week there was no significant change in surface area. Initially the mean surface area of wounds was $120.5 \mathrm{~cm}^{2}$ in NPWT group and 128.4 $\mathrm{cm}^{2}$ in control group. The wound surface area reduced more as the time advanced more .The mean reduction in wound surface area at the end of $4^{\text {th }}$ week in group A and group B patients were $45.28 \mathrm{~cm}^{2}$ (SD 24.11) and $32.31 \mathrm{~cm}^{2}$ (SD 18.32). And this finding was also stastically significant $(\mathrm{p}=0.0186)$.

\section{Bacterial bioburden and c/s patterns of wound swabs}

In the beginning of the study 10 of 32 patients with NPWT and 11 of 32 patients of NSGD had wound infection. During the study new wound infection developed in 3 patients in group $\mathrm{A}$ and 
in 4 patients in group B. Therefore total wound infection cases were 13 in NPWT group and 15 in NSGD group. At the end of $3^{\text {rd }}$ week, $3(9.38 \%)$ patients in group A and $4(12.5 \%)$ patients in group $B$ had wound infection $(\mathrm{p}=0.688)$. In this study we found that there was no significant difference in bacterial clearance. The incidence of SSI was also not found to be significant in NPWT group.

\section{Time of wound closure}

Out of 32 patients of NPWT group, 17 patients had spontaneous closure of wound and 15 patients required secondary suturing (skin flap cover). In group B, 11 patients had spontaneous closure and 21 patients required skin flap cover. At the end of $4^{\text {th }}$ week, total $22(68.75 \%)$ patients of group A and $13(40.63 \%$ ) patients of group B had achieved complete wound closure (either spontaneous or skin flap cover) and the $\mathrm{p}$ value was 0.023 . At the end of $6^{\text {th }}$ week, all patients of group A had complete wound closure where 3 patients of group $B$ required conversion to NPWT.

\section{Discussion and Conclusion}

Compared to conventional dressing, NPWT has a number of advantages with fewer complications. It was found from various studies that NPWT is associated with faster wound healing as it removes wound exudate and interstitial fluid, promotes granulation tissue formation, decreases bacterial bioburden and wound volume. It increases tissue perfusion, promotes growth factors and renders the wound either for closure by secondary intension or prepares the wound bed for final closure by secondary suturing (skin flap closure). In our study we observed that the rate of disappearance of wound exudate was faster following application of NPWT. In the beginning of our study all patients of group A and group B had wound discharge. At the end of $3^{\text {rd }}$ week we noticed that 14(43.75\%) patients of group A and $22(68.75 \%)$ patients of group Bhad wound discharge, where the $\mathrm{p}$ value was 0.043 .This study correlates with the study conducted by Argenta et $\mathrm{al}^{1}$ where 300 wounds were treated by VAC. Out of 300 wounds, 296 wounds responded favorably to subatmospheric pressure treatment. It was seen that this technique removed chronic oedema, leading to increased localized blood flow and enhanced granulation tissue formation. Stannard et $\mathrm{al}^{19}$ also conducted a study on 44 patients with traumatic wounds and found that wound exudation ceased earlier in the NPWT group than in pressure dressing group [1.6(0-5) vs 3.1 (0-11) days, $\mathrm{p}=0.03]$.In our study, wound exudate disappeared in all patients of group $A$ at $6^{\text {th }}$ week where $3(9.38 \%)$ patients of group B had continued wound discharge.

At the end of $2^{\text {nd }}$ week, our data showed that granulation tissue appeared in 29(90.625\%) patients in group A and 22(68.75\%)in group B, where the $p$ value is 0.029 . Our study is consistent with the study conducted by Morykwas M.J. et $\mathrm{al}^{7}$ who conducted 4 studies on pig model to observe the effect of negative pressure on wounds and adjacent tissue and found a significantly increased rates of granulation tissue formation $(\mathrm{p}<$ or $=0.05)$.

Disappearance of wound exudate and appearance of granulation tissue depended on duration of treatment in both groups. However, analyzing the results of our study we found that $3(9.38 \%)$ patients of group B had continuing wound discharge at 6 week of NSGD. Among these three patients, granulation tissue did not appear in 2 patients. At the end of $6^{\text {th }}$ week, these 3 patients effectively received NPWT and we revealed that following NPWT, wound discharge disappeared within 2 weeks and healthy granulation tissue appeared for split skin flap closure. This finding also proves that NPWT is more effective in dealing with complex chronic wounds than NSGD.

It was also seen in our study that the surface area of wound reduced more in NPWT group compared to control group. At the end of $2^{\text {nd }}$ and $3^{\text {rd }}$ week mean reduction of surface area in NPWT group were not significant. At the end of $4^{\text {th }}$ week, the mean reduction in surface area of wound in group A and group B patients were $45.28 \mathrm{~cm}^{2}$ 
$(\mathrm{SD} 24.11)$ and $32.31 \mathrm{~cm}^{2}(18.32)$ respectively. Again this finding was found to be significant $(\mathrm{p}=0.0186)$. The wound depth was reduced more than surface area in both groups. Etoz et $\mathrm{al}^{20}$ also conducted a randomized study on 24 diabetic patients and divided it into NPWT group and control group. .Mean duration of wound care were 11.25 vs 15.75 days. Mean reduction of surface area in group A and group B were $20.4 \mathrm{~cm}^{2}$ and9.5 $\mathrm{cm}^{2}$ where $\mathrm{p}$ value was 0.032 .

The most common organisms found in wound infection were staphylococcus aureus, streptococcus pyogens, enterococci and pseudomonas aeruginosa. In this study, it was noted that there was no significant difference in bacterial clearance in contaminated wounds $(\mathrm{p}=0.688)$. Some studies conveyed that NPWT was associated with increased bacterial clearance ${ }^{21}$, whereas other studies quoted that NPWT was responsible for increased bacterial colony ${ }^{11}$. Moues CM et al in his study found that the total quantitative bacterial load was stable. But nonfermentative gram negative bacilli showed a significant decrease in VAC treated wounds $(\mathrm{P}<0.05)$, and Staphylococcus aureus showed a significant increase in VAC treated wound $(\mathrm{p}<0.05)$. However, in our study, culture negative wounds showed reduced number of postoperative infection (SSI) ${ }^{9,10}$ following NPWT (3 vs 4 cases).This finding correlated with Grauhan $\mathrm{O}$ et $\mathrm{al}^{10}$ who conducted a study on 150 cases to detect the role of NPWT in preventing poststernotomy wound infection in obese patients and found a significantly reduced incidence of wound infection after median sternotomy.

We also observed in our study that NPWT lead to faster rate of wound healing. At the end of $4^{\text {th }}$ week 22 patients of NPWT group and 13 patients of NSGD group achieved wound closure either spontaneously or by skin flap $\operatorname{cover}(\mathrm{p}=0.023)$. Most of the studies correlate with this finding and shows a significantly faster rate of wound healing ${ }^{20}$.

Finally we found that NPWT was associated with more pain during dressing changes due to in growth of granulation tissue into foam ${ }^{20}$, superficial skin necrosis, peri wound blistering, reduced number of dressing changes and reduced hospital stay. The coast of NPWT appeared to be more. But, as a whole NPWT was coast effective if we consider other coast related factors. ${ }^{22}$

\section{References}

1. Argenta I.C, Morykwas MJ: Vacuum assisted closure: A new method for wound control and treatment: Clinical experience. Ann plast surg 38:563-576; discussion 577, 1997.

2. Joseph E, Hamori CA, Bergman S et al: A prospective randomized trial of vacuumassisted closure versus standard therapy of chronic non healing wounds 12:6067,2000 .

3. Timmers MS, L.C Cessie S, Banwell P, et al: The effects of varying degrees of pressure delivered by negative-pressure wound therapy on skin perfusion. Ann Plast Surg 55:665-671, 2005.

4. Chen SZ, Li J, Li XY, et al: Effects of vacuum-assisted closure on wound microcirculation: An experimental study. Asian J Surg 28:211-217, 2005.

5. Sibbald RG, Maleoney J,V.A.C. therapy Canadian consensus group. A consensus report on the use of vacuum-assisted closure in chronic, difficult to- heal wounds. Ostomy wound manage 2003;49(11) 52-66.

6. Sinha K., Chauhan V.D., Mahashwari R., Chauhan N., Ranjan M., Agrawal A. Vacuum assisted closure therapy versus standard wound therapy for open musculoskeletal injuries. Adv orthop. 2013[PMC free article][Pub Med].

7. Morykwas M.J., Argenta L.C.,SheltonBrown E.I, McGuirt W: Vacuum-assisted closure: a new method for wound control animal studies and basic foundation. Ann Plast Surg, 38(1997),pp 553-562. 
8. Tan A. Smith S.F. et al: Should infected laparotomy wounds be treated with negative pressure wound therapy?: Science Direct: International journal of surgery. Volume 12,Issue1, January 2014, Page2629.

9. Li P.Y., Yang D.,Liu D.et al: Reducing surgical site infection with negative pressure wound therapy after open abdominal surgery: A prospective randomized controlled study. Scandinavian journal of surgery, Sept-8,2016.

10. Grauhan O, Hetzer R. et al: Prevention of post sternotomy wound infection in obese patients by negative pressure wound therapy. The Journal of thoracic and cardiovascular surgery. Vol-145, Issue 5, May 2013, Pages-1387 to 1392.

11. Weed, Tonja; Raflift, Catherine RN; Drake, David B: Quantifying bacterial bioburden during negative pressure wound therapy: Does the wound V.A.C enhance bacterial clearance? Ann. Plastic Surg. March 2004-vol 52. Issue 3-p 276-279.

12. Moue"s CM, et al: Bacterial load in relation to vacuum-assisted closure wound therapy: a prospective randomized trial. Wound Repair Regen.2004 Jan-Feb.[Pub Med]

13. Mendez-Eastman $S^{1}$.: Negative pressure wound therapy. Plast. Surg. Nurs.1998, spring; 18(1):27-9, 33-7.

14. Schwien T, Gilbert J, Lang C. Pressure ulcer prevalence and the role of Negative Pressure Wound Therapy in home health quality outcomes. Ostomy Wound Manage.2005; 47-60.[Pub Med].

15. Moisidis E, Health T, Booren C, Ho K, Deva AK. Aprospective, blinded, randomized controlled clinical trial of topical negative pressure use in skin grafting. Plast Reconstr Surg.2004; 114:917-22.[Pub Med].
16. Etoz A', Kahveci R et al: Negative Pressure Wound Therapy on diabetic foot ulcer.Wounds.2007 Sept; 19(9):250-4.

17. Kantak NA, Mistry R, Varon DE, Halvorson EG: Negative pressure wound therapy for burns. Clin. Plast. Surg. 2017 Jul;44(3): 671-677.

18. KCL clinical guidelines, $\mathrm{p}-4$.

19. J.P. Stannard, J.T. Robinson, E.R. Anderson, G. McGwin Jr ,D.A. Volgas, J.E. Alonso: Negative pressure wound therapy to treat hematomas and surgical incisions following high energy trauma. J Trauma,60 (2006),pp.1301-1306.

20. Etoz A, Ozgenei Y, Ozcan M: The use of negative pressure wound therapy on diabetic foot ulcer: a preliminary controlled trial. Wounds, 16(2004), vol 16, issue 8, pp 264-269.

21. Daniel de Alcantara Jones, Wilson Vasconcelos Neves Filho, Janice de Souza Guimaraes, Daniel de Araujo Castro, Antonio Marcos Ferracini:The use of negative pressure wound therapy in the treatment of infected wounds. Casestudies. Rev Bras Ortop.2016 Nov-Dec;51(6):646651.

22. Upton D, Stephens D, Andrews A: Patient's experiences of negative pressure wound therapy for the treatment of wounds: a review. J Wound Care.2013 Jan;22(1):34-9. 